GRASAS Y ACEITES 67 (3)

July-September 2016, e142

ISSN-L: 0017-3495

doi: http://dx.doi.org/10.3989/gya.1237153

\title{
Free radical scavenging and $\alpha$-glucosidase inhibition, two potential mechanisms involved in the anti-diabetic activity of oleanolic acid
}

\author{
J.M. Castellano ${ }^{\mathrm{a}, \bigotimes}$, A. Guinda ${ }^{\mathrm{a}}$, L. Macías ${ }^{\mathrm{a}}$, J.M. Santos-Lozano ${ }^{\mathrm{b}, \mathrm{c}}$, J. Lapetra ${ }^{\mathrm{b}, \mathrm{d}}$ and M. Rada ${ }^{\mathrm{a}}$ \\ ${ }^{a}$ Instituto de la Grasa. CSIC. Food and Health Department. Campus of University Pablo de Olavide. Seville, Spain \\ ${ }^{\mathrm{b} C I B E R}$ Physiopathology of Obesity and Nutrition (ciberobn). Instituto de Salud Carlos III. Madrid, Spain \\ ${ }^{c}$ Department of Family Medicine. Primary Care Health District Seville. Primary Care Center San Pablo. Seville, Spain \\ ${ }^{\mathrm{d} D}$ Department of Family Medicine. Research Unit. Primary Care Health District Seville. Seville, Spain \\ Corresponding author: jmcas@ig.csic.es
}

Submitted: 04 December 2015; Accepted: 17 February 2016

SUMMARY: This work investigates the role of oleanolic acid (OA), isolated from the olive (Olea europaea L.) leaf, as a radical scavenger and inhibitor of the hydrolyzing enzymes of dietary carbohydrates. New evidence is provided showing that OA may capture 2,2'-azino-bis (3-ethylbenzothiazoline-6-sulphonic acid) and peroxyl radicals, and also exert a strong and non-competitive inhibition of $\alpha$-glucosidase $\left(\mathrm{IC}_{50} 10.11 \pm 0.30 \mu \mathrm{M}\right)$. The kinetic and spectrometric analyses performed indicate that OA interacts with this enzyme inside a hydrophobic pocket, through an endothermic and non spontaneous process of a hydrophobic nature. These are two possible mechanisms by which OA may facilitate a better control of post-prandial hyperglycaemia and oxidative stress, so contributing to preserving insulin signalling. Obesity, insulin resistance and Type 2 Diabetes Mellitus are considered the first pandemics of the 21st century. In this sense, OA might be used in future preventive and therapeutic strategies, as an ingredient in new drugs and functional foods.

KEYWORDS: Anti-diabetic activity; Antioxidant; $\alpha$-glucosidase inhibitor; Olea europaea; Oleanolic acid

RESUMEN: La Captación de radicales libres y la inhibición de a-glucosidasa, dos posibles mecanismos involucrados en la actividad antidiabética del ácido oleanólico. Este trabajo estudia el papel del ácido oleanólico (OA), aislado de la hoja de olivo, como secuestrador de radicales libres e inhibidor de enzimas implicados en la hidrolisis de los carbohidratos de la dieta, dos mecanismos por los que el triterpeno podría mitigar la hiperglicemia postprandial y el estrés oxidativo. Se aportan nuevas evidencias que muestran que el OA puede capturar radicales ácido 2,2'-azino-bis-(3-etilbenzotiazolín)-6-sulfónico y peroxilo, y que ejerce una potente inhibición nocompetitiva de $\alpha$-glucosidasa $\left(\mathrm{IC}_{50} 10.11 \pm 0.30 \mu \mathrm{M}\right)$. El análisis cinético y espectrométrico llevado a cabo indica que OA interacciona con este enzima en el interior de un bolsillo hidrofóbico, mediante un proceso endotérmico no espontáneo, de naturaleza hidrofóbica. Estos son dos posibles mecanismos por los cuales el OA puede facilitar un mejor control de la hiperglucemia postprandial y el estrés oxidativo, lo que contribuye a preservar la señalización de la insulina. La obesidad, la resistencia a la insulina y la diabetes mellitus tipo 2 se consideran la primera pandemia del siglo XXI. En este sentido, el OA podría ser utilizado en futuras estrategias preventivas y terapéuticas, como ingrediente de nuevos fármacos y alimentos funcionales.

PALABRAS CLAVE: Acción antidiabética; Ácido oleanólico; Antioxidante; Inhibidor de a-glucosidasa; Olea europea

Citation/Cómo citar este artículo: Castellano JM, Guinda A, Macías L, Santos-Lozano JM, Lapetra J, Rada M. 2016. Free radical scavenging and $\alpha$-glucosidase inhibition, two potential mechanisms involved in the anti-diabetic activity of oleanolic acid. Grasas Aceites 67 (3): e142. doi: http://dx.doi.org/10.3989/gya.1237153.

Copyright: (C) 2016 CSIC. This is an open-access article distributed under the terms of the Creative Commons Attribution-Non Commercial (by-nc) Spain 3.0 Licence. 


\section{INTRODUCTION}

Type 2 Diabetes Mellitus (T2DM), the most common form of the disease affecting near $90 \%$ of diabetic people, is recognized as a redox disorder, in which oxidative stress is a primary event underlying insulin resistance, $\beta$-cell failure, and longterm diabetes complications (Watson, 2014). This prompted investigations on the therapeutic use of antioxidants, although none of such studies demonstrated clear effects on the metabolic control of diabetic people (Ceriello and Testa, 2009). Another strategy to minimize oxidative stress is by reducing glycaemia fluctuations during post-prandial periods, since different studies with cells exposed to levels of glucose elevated intermittently have demonstrated the increased expression of biomarkers for oxidative stress (Quagliaro et al., 2003). An interesting approach is the inhibition of enzymes involved in carbohydrate breakdown and the intestinal absorption of glucose. Salivary and pancreatic $\alpha$-amylases (EC 3.2.1.1) cleaves the $\alpha-(1 \rightarrow 4)$ bonds of starch yielding shorter linear and branched dextrins, which are subsequently hydrolyzed at the non-reducing end into glucose by $\alpha$-glucosidase (EC 3.2.1.20) in the small-intestinal brush border membrane. Synthetic inhibitors, such as acarbose, voglibose or miglitol, are widely used in the clinic. However, the appearance of adverse effects is frequent, including flatulence, abdominal pain, nausea, vomiting, diarrhea, skin hypersensitivity, an elevation in the hepatic enzymes and even an increased incidence of renal tumors (Fujisawa et al., 2005).

Accordingly, the search for more effective and safer natural bio-molecules, with the dual ability to decrease glucose absorption and reduce oxidative damage, has become an important scientific goal. Oleanolic acid (OA) (3ß-hydroxy-olean-12en-28-oic acid), a pentacyclic triterpene widely distributed in the plant kingdom, has attracted the attention of researchers for its interesting pharmacological properties (Liu, 2005; Dzubak et al., 2006), including anti-diabetic activity (Castellano et al., 2013).

The data available nowadays concerning the antioxidant activity of OA are somewhat contradictory. Its ability to react with diverse radical species has been evaluated, having obtained an array of varied results (Yin and Chan, 2007; Yang et al., 2007; Wang et al., 2010; Allouche et al., 2011). The OA effect on $\alpha$-amylase is not completely clear (Khati et al., 2013; Wang et al., 2011). However, a consensus does exist concerning the efficient inhibition of $\alpha$-glucosidase by the triterpene, and some $\mathrm{IC}_{50}$ values in the micro-molar range have been reported (Ali et al., 2002; Kang et al., 2012). To our knowledge, studies on the mechanism of this reaction have not been carried out. Consequently, in this work, we investigate the triterpene's ability to scavenge three radical species (ABTS + , DPPH and peroxyl), and also to inhibit both $\alpha$-amylase as $\alpha$-glucosidase. The paper includes a deeper kinetic study to determine the type of inhibition, as well as fluorescent measurements to obtain new clues about the mechanism of the $\mathrm{OA} / \alpha$-glucosidase interaction. This research is part of a more general investigation aimed at exploiting the therapeutic potential of OA against diabetes.

\section{MATERIALS AND METHODS}

\subsection{Plant material, reagents and standards}

Olive (Olea europaea L. cv. Picual) leaves were hand-picked from adult trees ( $>10$ years old) from the experimental olive grove belonging to the Instituto de la Grasa-CSIC in Seville.

All solvents used were of analytical grade. Betulinic acid; hexamethyldisilazane; trimethylchlorosilane; 2,2'-azino-bis(3-ethylbenzothiazoline-6-sulphonic acid) (ABTS); 2,2-Diphenyl-1-picrylhydrazyl (DPPH); 2,2'-azobis (2-amidinopropane) dihydrochloride (AAPH); fluorescein; pancreatic $\alpha$-amylase; potato starch; 3,5-dinitrosalicylic acid; sodium potassium tartrate; $\alpha$-glucosidase from Saccharomyces cerevisiae; 4-nitrophenyl- $\alpha$-D-glucopyranoside ( $p$-NPG); and acarbose were purchased from Sigma-Aldrich (Sigma-Aldrich Quimica, Madrid, Spain).

\subsection{Isolation of oleanolic acid from O. europaea}

High purity OA was isolated from olive leaves according to the procedure described by us (Guinda et al., Patent 2001/2160553). Briefly, dry leaves were extracted by maceration with $96 \%$ ethanol, which was then percolated and subsequently reduced by vacuum. Solid OA was obtained by crystallization and filtration. Its chemical nature was confirmed by GC-MS (P Gutiérrez-Adánez, Thesis of Master, University Pablo de Olavide; Seville, 2013), and its purity was determined by differential scanning calorimetry (DSC) and GC-FID (Albi et al., 2001; Guinda et al., 2010).

\subsection{Derivatization of oleanolic acid}

The low volatility and high molecular weight of OA demands its derivatization prior to the GC analysis. The silylating reagent was prepared by mixing 3 $\mathrm{mL}$ of hexamethyldisilazane and $1 \mathrm{~mL}$ of trimethylchlorosilane with $9 \mathrm{~mL}$ of anhydrous pyridine. Ten milligrams of OA were dissolved in $20 \mathrm{~mL}$ absolute ethanol. An aliquot $(100 \mu \mathrm{L})$ of this solution and $100 \mu \mathrm{L}$ of $0.5 \mathrm{mg} / \mathrm{mL}$ betulinicacid (internal standard) were placed in $1 \mathrm{~mL}$ gas-tight vials and evaporated to dryness under a $\mathrm{N}_{2}$ stream. The residue was dissolved in $200 \mu \mathrm{L}$ of the silylating reagent and sonicated at $70{ }^{\circ} \mathrm{C}$ for $15 \mathrm{~min}$. The solution harboring 
the derivatized triterpene was analyzed by GC-FID and GC-MS.

\subsection{GC-FID Analysis}

The quantification of OA was carried out by a modification of the method described by us in (Guinda et al., 2010). Concisely, $1 \mu \mathrm{L}$ of the silylated sample was injected into an Agilent 6890N GC (Agilent Technologies, CA), equipped with a Rtx65TG Cross-bond capillary column $(30 \mathrm{~m} \times 0.25$ mm I.D.; $0.1 \mathrm{~mm}$ film thickness) coated with $35 \%$ dimethyl-65\% diphenyl polysiloxane as stationary phase (Restek, Co., Bellefonte, PA) and a FID detector. The injection was done in the split mode, and hydrogen was used as carrier gas (pressure at column head $140 \mathrm{kPa}$ ). The oven temperature was maintained at $260^{\circ} \mathrm{C}$, and the injector and detector temperatures at $300^{\circ} \mathrm{C}$.

\subsection{GC-MS identification of oleanolic acid}

The analysis of derivatized OA was performed using a coupled gas chromatograph-mass spectrometry detector (GC-MS) QP2010 Ultra (Shimadzu Europa $\mathrm{GmbH}$ ) fitted with an AOC-20i autosampler, an ion source of electron impact and a quadrupole detector. The splitless mode was used and the injector temperature was set at $290{ }^{\circ} \mathrm{C}$. Helium was the carrier gas at a pressure of $53.1 \mathrm{kPa}$ and a flow of $1 \mathrm{~mL} / \mathrm{min}$. The oven temperature program was as follow: initial temperature $50{ }^{\circ} \mathrm{C}$ for $1 \mathrm{~min}, 50-200{ }^{\circ} \mathrm{C}$ at $40{ }^{\circ} \mathrm{C} / \mathrm{min}, 200-280{ }^{\circ} \mathrm{C}$ at $10{ }^{\circ} \mathrm{C} / \mathrm{min}$, held at $280^{\circ} \mathrm{C}$ for $8.50 \mathrm{~min}$, and finally at $300{ }^{\circ} \mathrm{C}$ for $1 \mathrm{~min}$. Total run time: $24,25 \mathrm{~min}$. The MS conditions were: interface temperature: $280{ }^{\circ} \mathrm{C}$; ion source temperature: $220{ }^{\circ} \mathrm{C}$; electron impact: $70 \mathrm{eV}$; acquisition mode: scan (m/z 50-600). The identification of the OA trimethylsilyl derivative was accomplished by comparing the retention time and abundance ratio of two fragment ions (203 and $189 \mathrm{~m} / \mathrm{z}$ ) with those of the standard compound.

\subsection{Purity evaluation by DSC}

The OA purity was also assessed by Differential Scanning Calorimetry (DSC), following the method described in (Albi et al., 2001). A TA-Q2000 calorimeter equipped with a cooling unit (Thermal Analysis Instruments; Barcelona, Spain) was used. This instrument was calibrated with indium $(99.9 \%)$. The OA samples $(10-15 \mathrm{mg})$ were enclosed in hermetically sealed aluminum pans and analyzed against air (empty pans) as reference. The calorimeter chamber was previously thermostatized at $30{ }^{\circ} \mathrm{C}$ for $10 \mathrm{~min}$. Then, the melting curves from 30 to $350{ }^{\circ} \mathrm{C}$ (heating rate $10{ }^{\circ} \mathrm{C} / \mathrm{min}$ ) were recorded. The data were analyzed using the Peak Program software of the TA-Q2000.

\subsection{Radical scavenging}

\subsubsection{2,2'-azino-bis(3-ethylbenzothiazoline-6- sulphonic acid) (ABTS) assay}

The ABTS+ scavenging capacity was evaluated following a modification of the procedure by Re et al. (1999). The radicals were generated by oxidizing its precursor ABTS (7.0 $\mathrm{mM}$ in methanol) with potassium persulfate $(2.45 \mathrm{mM})$, maintaining the mixture overnight in the dark at room temperature. The resultant ABTS+ solution was diluted to have an absorbance at $734 \mathrm{~nm}$ in the range of $0.7-0.8$. An aliquot $(10 \mu \mathrm{L})$ of $\mathrm{OA}$ samples $(0.5,1.0,4.0$ and $10.0 \mathrm{mM}$ in methanol), or a blank (methanol), was added to $1 \mathrm{~mL}$ of the ABTS+ solution. The mixture was stirred and left to react in the dark at room temperature for $5 \mathrm{~min}$, and then the absorbance at $734 \mathrm{~nm}$ was recorded in a Beckman DU 640 UV-VIS light spectrophotometer (Beckman Coulter Inc.; Pasadena, CA; USA). The results were expressed as percentage of the initial absorbance of the ABTS+ solution. Butylated hydroxytoluene (BHT) $(0.5 \mathrm{mM}$ in methanol) was assayed as reference antioxidant.

\subsubsection{2,2-Diphenyl-1-picrylhydrazyl (DPPH) free radical scavenging test}

The OA ability to capture DPPH radicals was also assessed spectrophotometrically according to the revised protocol by Sharma and Bhat (2009). The reaction mixture $(4 \mathrm{~mL})$, containing $50 \mu \mathrm{M}$ DPPH alone or in the presence of OA $(1,25,50,100$ and $1000 \mu \mathrm{M}$ ), was incubated for $30 \mathrm{~min}$ at $30^{\circ} \mathrm{C}$ in the dark, and then the absorbance at $517 \mathrm{~nm}$ was measured using the Beckman DU 640 spectrophotometer. The scavenging activity was expressed as percentage of the initial absorbance of the DPPH solution. BHT (50 and $100 \mu \mathrm{M})$ was also included in the assay as a positive control.

\subsubsection{Oxygen Radical Absorbance Capacity (ORAC) Assay}

The ORAC assay was performed following a modification of the procedure reported by Prior et al. (2003), in which fluorescein was the target of the peroxyls generated with 2,2'-azobis (2-amidinopropane) dihydrochloride (AAPH). An aliquot $(20 \mu \mathrm{L})$ of the OA sample [0.1-0.7 mM in $10 \%$ DMSO (in $75 \mathrm{mM}$ phosphate buffer, $\mathrm{pH} 7.4$ at $37^{\circ} \mathrm{C}$ )] or a blank (buffered DMSO) was pre-incubated with $120 \mu \mathrm{L}$ of $116.7 \mathrm{nM}$ fluorescein for $10 \mathrm{~min}$ at $37^{\circ} \mathrm{C}$. Then, the reaction was started by the addition of $60 \mu \mathrm{L}$ of $40 \mathrm{mM}$ AAPH. The time course of the fluorescent decay ( $\lambda$ ex $=485 \mathrm{~nm}, \lambda \mathrm{em}=525 \mathrm{~nm}$ ) was recorded for 80 min using a Fluostar Galaxy plate reader (BMG Labtechnologies, Offenburg, Germany). The capacity to scavenge peroxyl radicals correlates with the 
net area under the fluorescent decay curve (AUC), calculated by subtracting the OA sample AUC from the blank AUC. The AUCs were automatically calculated by the Fluostar software. The ORAC value (expressed as the $\mu \mathrm{mol}$ Trolox equivalent), was determined from the calibration curve obtained with standard Trolox in the concentration range $1-10 \mu \mathrm{M}$.

\subsubsection{Rancimat method}

Rancimat 743 equipment (Metrohm AG; Erisau, Switzerland) was used for evaluating the role of $\mathrm{OA}$ against lipid peroxidation. An aliquot $(300 \mu \mathrm{L})$ of OA solutions ( 0.5 and $1.0 \mathrm{mM}$ in DMSO) was added to $3.0 \mathrm{~g}$ of olive or sunflower oil. The mixture was heated at $100{ }^{\circ} \mathrm{C}$ whereas an air flow $(20 \mathrm{~L} / \mathrm{h})$ bubbled constantly. The effluent gas was collected in de-ionized water, whose electrical conductivity was continuously monitored. In this system, the antioxidant activity correlates with the extension of timing up to the inflection point in the conductivity curve (induction time) (Burkow et al., 1995). The antioxidant activity index (AAI) was calculated from the ratio induction time of the oil with OA/induction time of oil alone. BHT $(250$ and $500 \mu \mathrm{g} / \mathrm{g})$ was likewise included in the assays as a reference antioxidant.

\subsection{In vitro inhibition of carbohydrate hydrolyzing enzymes}

\subsubsection{In vitro assay for $\alpha$-amylase}

$\alpha$-Amylase was assayed using the chromogenic method adopted by Sigma-Aldrich (www. sigmaaldrich.com/technical-documents/protocols/ biology/enzymatic-assay-of-a-amylase.html). Porcine pancreatic $\alpha$-amylase was dissolved in an ice-cold $20 \mathrm{mM}$ sodium phosphate buffer (pH 6.9 at $37^{\circ} \mathrm{C}$ ) containing $6.7 \mathrm{mM} \mathrm{NaCl}$. The potato starch solution $(1 \% \mathrm{w} / \mathrm{v})$ was prepared in the same buffer.

In a first series of experiments, $40 \mu \mathrm{L}$ of OA solutions (5-1000 $\mu \mathrm{M}$ in buffered $10 \%$ DMSO), $60 \mu \mathrm{L}$ of phosphate buffer, and $400 \mu \mathrm{L}$ of the substrate solution were mixed in a screw-top glass tube, and pre-incubated at $37{ }^{\circ} \mathrm{C}$ for $5 \mathrm{~min}$. The reaction was subsequently started by the addition of $200 \mu \mathrm{L}$ of the enzyme solution ( 1 unit $/ \mathrm{mL})$, and the mixture was incubated at the same temperature for $5 \mathrm{~min}$. Then, $350 \mu \mathrm{L}$ of the DNS color reagent $(96 \mathrm{mM} 3,5$-dinitrosalicylic acid, $5.31 \mathrm{M}$ sodium potassium tartrate in $2 \mathrm{M} \mathrm{NaOH}$ ) were added to the tube and placed into a $85{ }^{\circ} \mathrm{C}$ water bath for $15 \mathrm{~min}$. Then, the mixture was removed and diluted with $3 \mathrm{~mL}$ distilled water. The maltose generated in the reaction (absorbance at $540 \mathrm{~nm}$ ) was quantified from the calibration curve obtained with standard maltose in the range of $50 \mu \mathrm{M}-3.75 \mathrm{mM}\left(\mathrm{A}_{540}=2.6185 \cdot 10^{-4}\right.$ [maltose] $\left.0.0279 ; r^{2}=0.9972\right)$. Control incubations representing $100 \%$ enzyme activity were conducted in an identical fashion, replacing the OA solution by DMSO. Blank incubations, where the enzyme solution was replaced with phosphate buffer, were also included. In a second series of assays, the enzyme was pre-incubated with $\mathrm{OA}$ at $37^{\circ} \mathrm{C}$, and the reaction was started by the addition of the starch solution. In both series, acarbose $(20 \mu \mathrm{M})$ was introduced as a reference inhibitor.

\subsubsection{In vitro assay for $\alpha$-glucosidase}

The $\alpha$-glucosidase activity was tested by adapting the protocol by Kang et al. (2011) to 96-well microplates. To each well, $30 \mu \mathrm{L}$ of a $100 \mathrm{mM}$ phosphate buffer containing $100 \mathrm{mM} \mathrm{NaCl}\left(\mathrm{pH} 6.8\right.$ at $\left.37^{\circ} \mathrm{C}\right)$, $30 \mu \mathrm{L}$ of $2.5 \mathrm{mM} p$-NPG in this same buffer, and $30 \mu \mathrm{L}$ of OA $(0.05-50.0 \mu \mathrm{M}$ in buffered $10 \% \mathrm{DMSO})$, were added. The plate was pre-incubated at $37^{\circ} \mathrm{C}$ for $5 \mathrm{~min}$, and the reaction was started by adding $30 \mu \mathrm{L}$ of the $\alpha$-glucosidase solution $(0.2 \mathrm{U} / \mathrm{mL}$ $\alpha$-glucosidase in phosphate buffer). After $20 \mathrm{~min}$ at the same temperature, $120 \mu \mathrm{L}$ of $100 \mathrm{mM}$ sodium carbonate were added to stop the reaction. The release of 4-nitrophenol $\left(\varepsilon=18.3 \mathrm{mM}^{-1} \mathrm{~cm}^{-1}\right)$ was determined by measuring the absorbance at $405 \mathrm{~nm}$ in a Multiskan Spectrum (Thermo Labsystems; Milford, MA, USA) micro-plate reader. One enzyme activity unit is defined by the release of $1.0 \mu \mathrm{mol}$ $\alpha$-D-glucopyranoside per minute at $37^{\circ} \mathrm{C}$. Control incubations representing $100 \%$ enzyme activity were conducted, replacing OA solutions with DMSO. Likewise, blank incubations were carried out where the enzyme solution was replaced by the phosphate buffer. The inhibitory activity of OA was assayed in the range of $0.05-50.0 \mu \mathrm{M}$, and $20 \mu \mathrm{M}$ acarbose was introduced as reference inhibitor.

\subsubsection{Fluorescence quenching measurements}

In these experiments, $\alpha$-glucosidase was assayed at $1 \mu \mathrm{M}$ in the presence of $\mathrm{OA}(0-25 \mu \mathrm{M})$. The reaction mixture (whose final volume was brought to $4.0 \mathrm{~mL}$ with phosphate buffer) was incubated for 10 min at 20,30 and $37^{\circ} \mathrm{C}$. The fluorescent spectra of $\alpha$-glucosidase were obtained on a Cary Eclipse fluorescence spectrophotometer (Agilent Technologies; Santa Clara, CA, USA) equipped with a $10.0 \mathrm{~mm}$ quartz cell and a thermo-stated bath. The excitation wavelength was $280 \mathrm{~nm}$, and the emission spectra were recorded from 300 to $500 \mathrm{~nm}$. The excitation and emission bandwidths were both set at $5 \mathrm{~nm}$. Appropriate blanks corresponding to the phosphate buffer alone were assayed and subtracted to correct background fluorescence.

\subsection{Statistical analysis}

All data are presented as the means \pm standard deviation (SD) from a series of three independent experiments carried out with five replicates. The 
data were evaluated by a one-way ANOVA with the SigmaPlot 12.5 software (SPSS, Inc., Chicago, IL), and the differences between means were assessed using the Duncan's multiple-range test. Statistical significance was considered at $\mathrm{p}<0.05$.

\section{RESULTS}

\subsection{Obtaining pure oleanolic acid from olive leaf title One}

Eighteen grams and six hundred thirty two milligrams of crystallized OA were obtained from one kilogram of dried olive leaves. Its purity $(98.6 \%)$ was determined by both GC-FID and DSC (data not shown).

\subsection{Free radical scavenging}

\subsubsection{2,2'-azino-bis (3-ethylbenzothiazoline-6- sulphonic acid) (ABTS+) assay}

The stable radical ABTS+ is commonly used for the estimation of total antioxidant capacity. The simpler and more frequently applied approach of this assay consists of analyzing the activity of a sample against pre-formed radicals. With this scheme, we have found that OA is a moderate scavenger of ABTS+, and its action is dose-dependent (Table 1). Thus, $10 \mathrm{mM}$ OA removed $24 \%$ of the initially present ABTS+. In comparison, $0.5 \mathrm{mM}$ BHT abolished these radicals almost completely. On the other hand, we have tested two other solvents in addition to methanol, for preparing the OA solutions: carboxymethylcellulose (CMC) and DMSO, but they did not improve the scavenging activity of the triterpene.

\subsubsection{2,2-Diphenyl-1-picrylhydrazyl (DPPH) free radical scavenging test}

DPPH is also very common for the study of natural antioxidants. Its solutions have a characteristic deep purple color $(\lambda \max 515-517 \mathrm{~nm})$ that decolorize by the action of radical scavengers. Performing this procedure, it became evident that OA does not capture DPPH radicals, at least at concentrations lower than $1 \mathrm{mM}$ (data not shown). The use of DMSO substituting for methanol as the triterpene solvent did not provide better results.

\subsubsection{Oxygen Radical Absorbance Capacity (ORAC) Assay}

The ORAC assay determines the ability of a compound to preserve fluorescein from the attack of peroxyls generated with AAPH. Using this method, OA showed a low and dose-dependent capability to react with these radicals (Figure 1). The net areas
TABLE 1. Scavenging of the ABTS+ radical by oleanolic acid. Results are expressed as the means \pm SD $(n=15)$. $\mathrm{CMC}=$ carboxymethylcellulose $[2.5 \%(\mathrm{w} / \mathrm{w})]$. BHT was included in the assay as positive control. Different letters within a column indicate that values are different at $p<0.05$

\begin{tabular}{lcc}
\hline & $\begin{array}{c}\text { absorbance } \\
\left(\boldsymbol{\lambda}_{734}\right)\end{array}$ & reduction (\%) \\
\hline ABTS+ & $0.779 \pm 0.041^{\mathrm{a}}$ & \\
+ OA $(\mathrm{mM})$ in methanol & & \\
0.5 & $0.682 \pm 0.035^{\mathrm{b}, \mathrm{d}}$ & $12.5 \pm 0.6$ \\
1.0 & $0.676 \pm 0.038^{\mathrm{b}, \mathrm{d}}$ & $13.2 \pm 0.7$ \\
4.0 & $0.645 \pm 0.047^{\mathrm{b}, \mathrm{e}}$ & $17.2 \pm 1.2$ \\
10.0 & $0.586 \pm 0.030^{\mathrm{c}, \mathrm{h}}$ & $24.8 \pm 1.3$ \\
+ OA $(\mathrm{mM})$ in CMC & & \\
0.5 & $0.691 \pm 0.054^{\mathrm{d}}$ & $11.2 \pm 0.9$ \\
1.0 & $0.673 \pm 0.034^{\mathrm{b}, \mathrm{d}, \mathrm{f}}$ & $13.5 \pm 0.7$ \\
4.0 & $0.636 \pm 0.032^{\mathrm{e}, \mathrm{f}, \mathrm{h}}$ & $18.4 \pm 0.9$ \\
+ OA $(\mathrm{mM})$ in DMSO & & \\
4.0 & $0.631 \pm 0.028^{\mathrm{e}, \mathrm{g}, \mathrm{h}}$ & $18.9 \pm 0.9$ \\
10.0 & $0.599 \pm 0.031^{\mathrm{h}}$ & $23.2 \pm 1.2$ \\
+ BHT $0.5 \mathrm{mM}$ & $0.026 \pm 0.002^{\mathrm{i}}$ & $96.7 \pm 3.5$ \\
\hline
\end{tabular}

under the fluorescent decay curves were linearly fitted to the OA concentrations in the range of $0.1-0.7$ $\mathrm{mM}$. An ORAC value of $1.628 \mathrm{nmol}$ Trolox equiv/ $\mu \mathrm{mol}$ OA was determined from the calibration curve obtained with standard Trolox (Net AUC $=19.904$ nmol Trolox $\left.+6.335 ; r^{2}=0.9899\right)$.

\subsubsection{Rancimat method}

The Rancimat method, based on the induction of lipid oxidation by exposure to airflow at high temperatures, is likely the most commonly used procedure for measuring the oxidative stability of oils and fats. The process occurs via a chain reaction (with participation of hydroxyl and peroxyl radicals), in which the double bonds of unsaturated fatty acids undergo cleavage, releasing volatile short-chain organic acids, aldehydes and ketones. The reaction is characterized by a relatively slow initial period before it suddenly speeds up. The time for this to happen, called induction time, is taken as an indication of the oxidative stability of the lipid sample. The Rancimat procedure can be also applied for assessing the efficiency of antioxidants, by appraising how long they are able to prolong the initial induction step. This paper reports the use of such equipment for evaluating the antioxidant potential of OA for the first time.

We first ran experiments with an olive oil, chosen by its low content in minor components. In this lipid system, $0.5 \mathrm{mM}$ OA did not prevent oil oxidation, but instead it exerted a slight pro-oxidant activity, as 


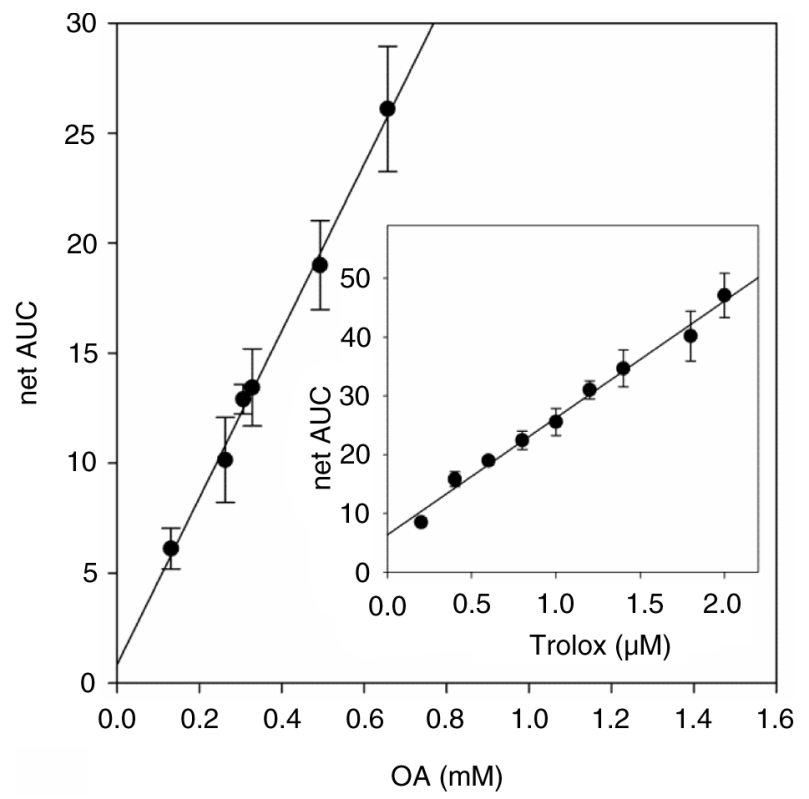

FIGURE 1. Oxygen radical absorbance capacity (ORAC) assay for OA. Net area under the fluorescent decay curve in the presence of increasing concentrations of OA. The inset is the calibration curve obtained with standard Trolox. Results are expressed as mean $\pm \mathrm{SD}$ of three independent experiments carried out with five replicates.

evidenced by the shortening of the induction period (Figure 2). By doubling the OA concentration in the medium no significant changes were observed. A second sequence of trials was performed with refined sunflower oil, whose triglycerides are richer in polyunsaturated fatty acids than those of olive oil. In that lipid matrix, the triterpene showed a clear and dose-dependent pro-oxidant action. So, in the presence of $1.0 \mathrm{mM} \mathrm{OA}$ the oxidative stability of the sunflower oil fell by $50 \%$. In both experimental series, BHT was able to remarkably delay oil oxidation. To the best of our knowledge, this is the first time a pro-oxidant action of OA is reported.

\subsection{Inhibition of carbohydrate hydrolyzing enzymes}

\subsubsection{Effect of $O A$ on the pancreatic $\alpha$-amylase}

$\alpha$-Amylase activity was assayed using potato starch as substrate to determine the maltose produced in the reaction. We performed two series of experiments, considering whether starch and OA were first pre-incubated and the reaction was started by the addition of the enzyme solution; or whether the enzyme was first pre-incubated with the triterpene and then the reaction initiated by addition of the substrate. With both approaches, no enzyme inhibition was observed in the OA concentration range $5.0 \mu \mathrm{M}-1.0 \mathrm{mM}$. However, $20 \mu \mathrm{M}$ acarbose (the reference inhibitor) was able to repress the
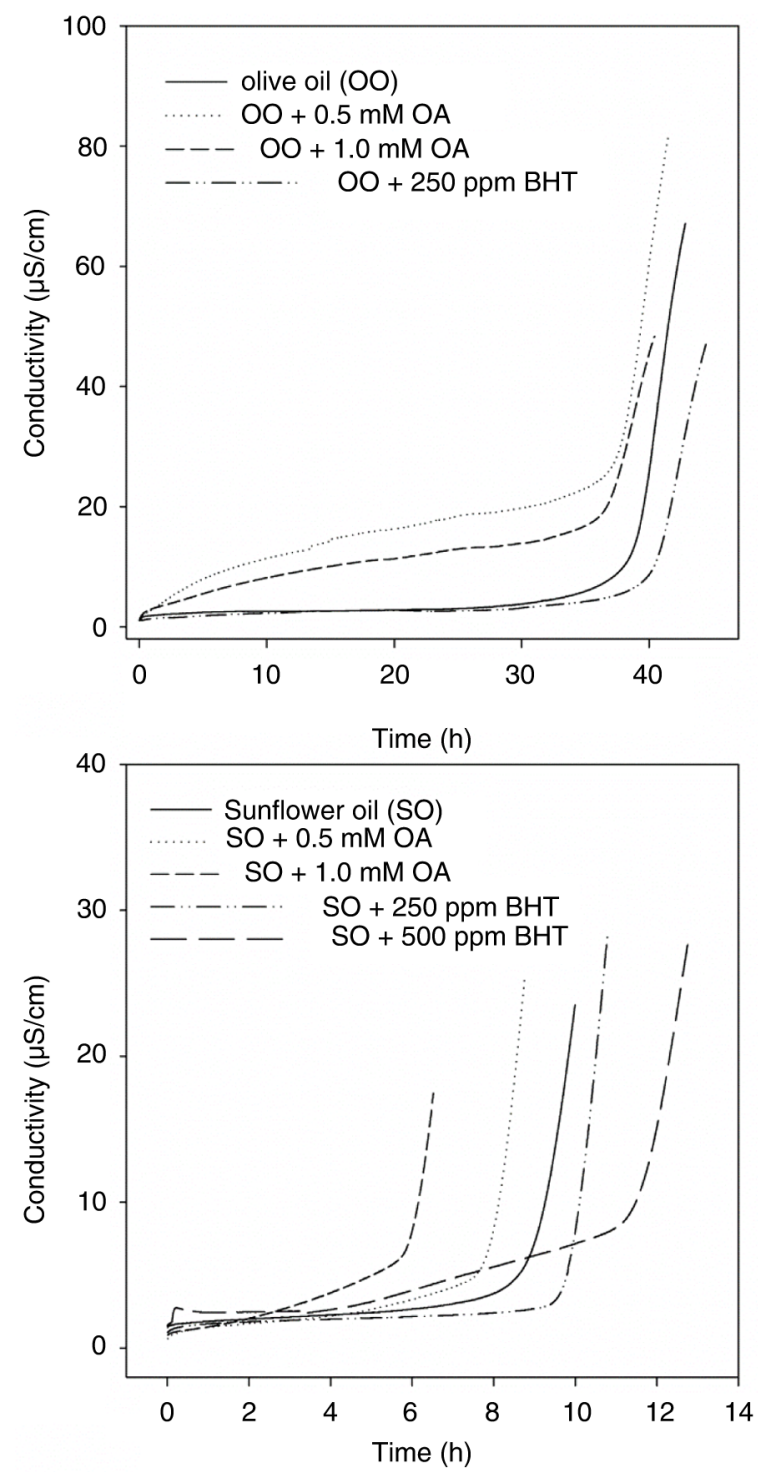

FIGURE 2. Effect of OA on the oxidative stability of olive and sunflower oils (Rancimat method). Typical conductivity $v s$ time curves representative of three independent experiments performed with five replicates.

enzyme activity by 27.2 and $30.1 \%$, respectively (data not shown).

\subsubsection{Inhibition of the $\alpha$-glucosidase activity by $O A$}

Unlike $\alpha$-amylase, OA caused a strong inhibition of the $\alpha$-glucosidase activity. This effect was dose-dependent, with the enzyme activity decreasing remarkably when the OA dose augmented (Figure 3 ). In fact, the $\alpha$-glucosidase action was virtually abolished at $20 \mu \mathrm{M}$ OA and above. The dose resulting in $50 \%$ inhibition $\left(\mathrm{IC}_{50}\right)$ was estimated to be $10.11 \pm 0.30 \mu \mathrm{M}$. 


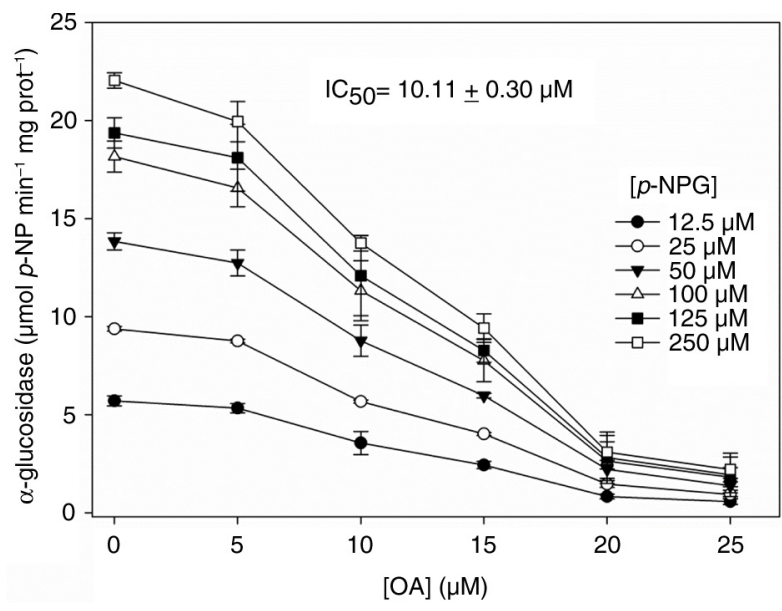

FIGURE 3. Inhibitory effect of OA on the $\alpha$-glucosidase activity. In the inset the OA dose resulting in 50\% inhibition $\left(\mathrm{IC}_{50}\right)$ is expressed. Results are expressed as mean $\pm \mathrm{SD}$ of three independent experiments carried out with five replicates.

For a deeper study of the inhibition mechanism we first corroborated that $\alpha$-glucosidase catalysis followed a Michaelis-Menten kinetic. The reaction proceeded at its maximum rate $(26.84 \mu \mathrm{mol}$ $p$-NP $\min ^{-1} \mathrm{mg}$ prot $^{-1}$ ) with substrate concentrations greater than $150 \mu \mathrm{M}$, and a $K m$ value of 51.34 $\mu \mathrm{M}$ was determined for $p$-NPG. We also studied the time-course of the reaction in the absence and presence of $\mathrm{OA}(5,15$ and $25 \mu \mathrm{M})$, finding that the activity $v s$ time relationship progressed linearly for at least 25 min (data not shown). Then, we evaluated the enzyme activity at increasing concentrations of $p-\mathrm{NPG}$, in the presence of different doses of OA. The Lineweaver-Burk's kinetic analysis of results indicated that $\mathrm{OA}$ was a non-competitive inhibitor of $\alpha$-glucosidase (Figure 4). The inhibition constant (Ki) of $9.12 \pm 0.24 \mu \mathrm{M}$ was calculated by both the Dixon and Cornish-Bowden analyses.

\subsubsection{Fluorescence quenching of $\alpha$-glucosidase by oleanolic acid}

The powerful inhibition that OA exerts on $\alpha$-glucosidase suggests that the triterpene directly binds to the protein. To achieve new evidence for this interaction, we conducted, for the first time to our knowledge, binding studies employing fluorescent spectroscopy. The spectra of $\alpha$-glucosidase in the presence of different $\mathrm{OA}$ concentrations were recorded at 20, 30 and $37^{\circ} \mathrm{C}$ (Figure 5). Under the same experimental conditions, OA did not display intrinsic fluorescence or UV-VIS absorption in the wavelength range $300-500 \mathrm{~nm}$, not interfering with the $\alpha$-glucosidase spectra (data not shown). $\alpha$-Glucosidase exhibited a strong fluorescent emission peak at $333 \mathrm{~nm}$ after excitation at $280 \mathrm{~nm}$, indicating that tryptophans located in inner regions

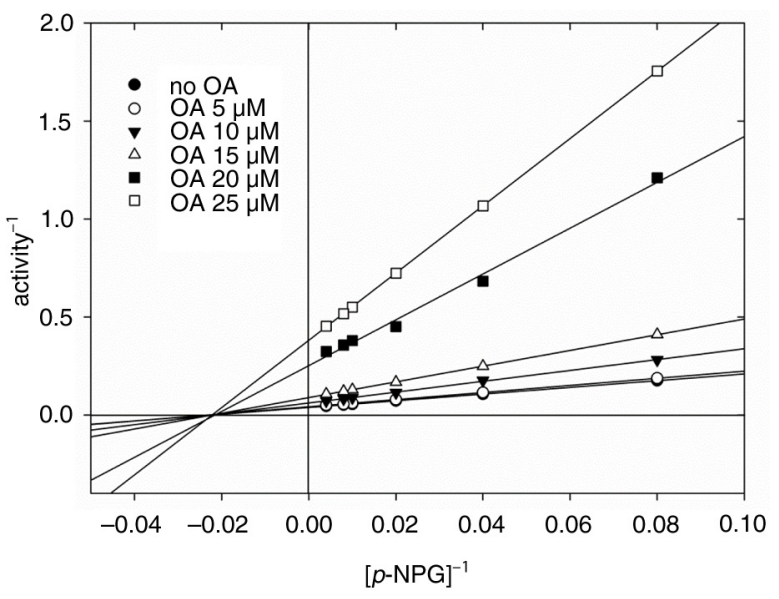

FIGURE 4. Lineweaver-Burk plots for the $\alpha$-glucosidase inhibition by $\mathrm{OA}$.

of the protein are practically the only ones emitting fluorescence. In the presence of OA, significant and dose-dependent decreases in the fluorescent intensity were observed. This quenching effect did not involve hypsochromic or bathochromic shifts, which reveals that the $\mathrm{OA} / \alpha$-glucosidase interaction only affected those tryptophyls positioned within a cleft of the enzyme.

Figure 6 shows the Stern-Volmer plots $\left(F_{0} / F=\right.$ $\left.1+K_{S V}[O A]\right)$ for the quenching of $\alpha$-glucosidase fluorescence by OA. In this equation, $F_{0}$ and $F$ denote the steady-state fluorescent intensities in the absence and presence of the triterpene, respectively; and $K_{S V}$ is the Stern-Volmer quenching constant, a measure of the interaction strength between the protein and its ligand. The plot's linearity illustrates that within the assayed concentration range, a single class of enzyme fluorophores is affected by OA. The results also show that the $K_{S V}$ values increased with increasing temperature, suggesting that quenching proceeded mainly through a dynamic mechanism of collisions between OA and tryptophans. This relationship may also be described by the equation $\log$ $[(F o-F) / F]=\log K_{A}+n \log [Q]$ (Yan et al., 2014), where $K_{A}$ is the binding constant, and $n$ the number of binding sites on the protein (Figure 6). It can be observed that both $K_{A}$ and $n$ rose with the increase in temperature, showing again that the $\mathrm{OA} / \alpha$ glucosidase interaction was favored under warmer conditions. Moreover, the values of $n$ show a trend to one, supporting the existence of a single class of binding site for $\mathrm{OA}$.

More information about this interaction may be inferred from the signs of the thermodynamic parameters in the process. The changes in enthalpy $(\Delta H)$ and entropy $(\Delta S)$ can be determined from the Van't Hoff equation [ln $K_{S V}=-(\Delta H / \mathrm{RT})+$ $(\Delta S / \mathrm{R})$; where $\mathrm{R}$ is the gas constant], and the free energy changes $(\Delta G)$ can be estimated from the 


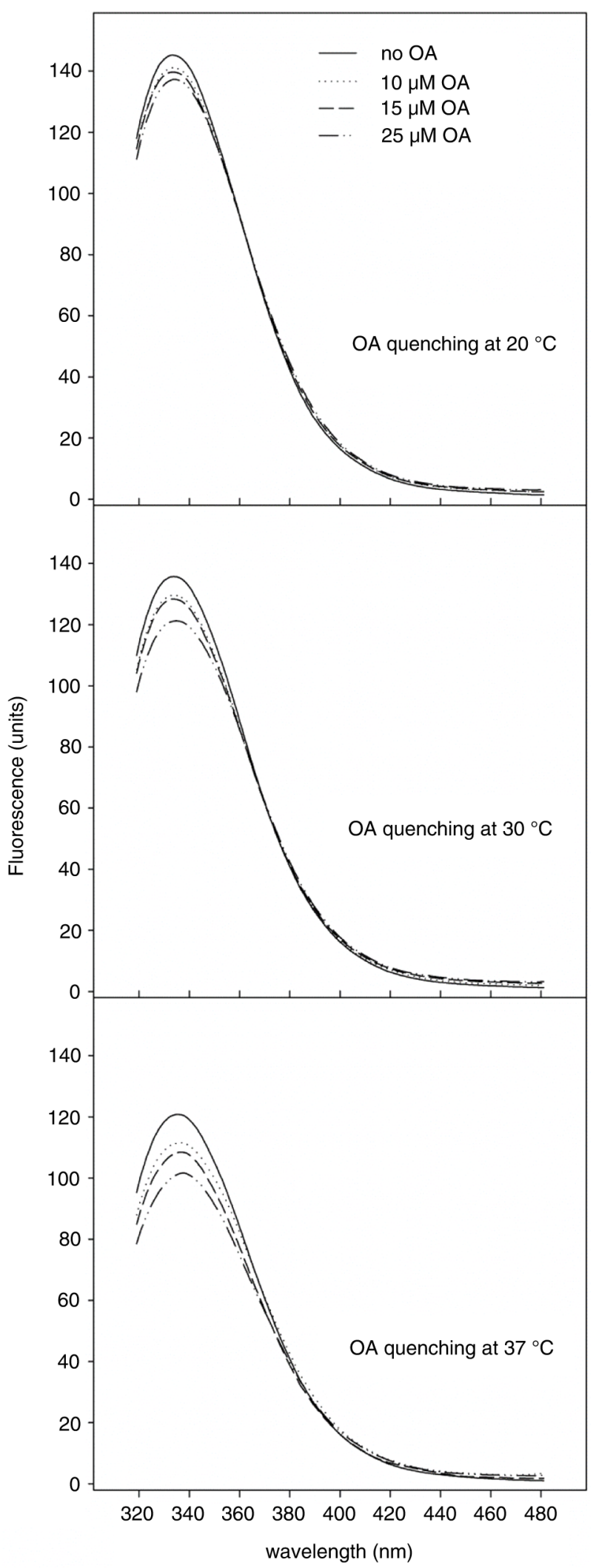

FIGURE 5. Fluorescent emission spectra (300-500 nm) of $\alpha$-glucosidase at 20,30 and $37^{\circ} \mathrm{C}$, in the presence of increasing concentrations of OA $\left(\lambda_{\mathrm{ex}}=280 \mathrm{~nm}\right)$.
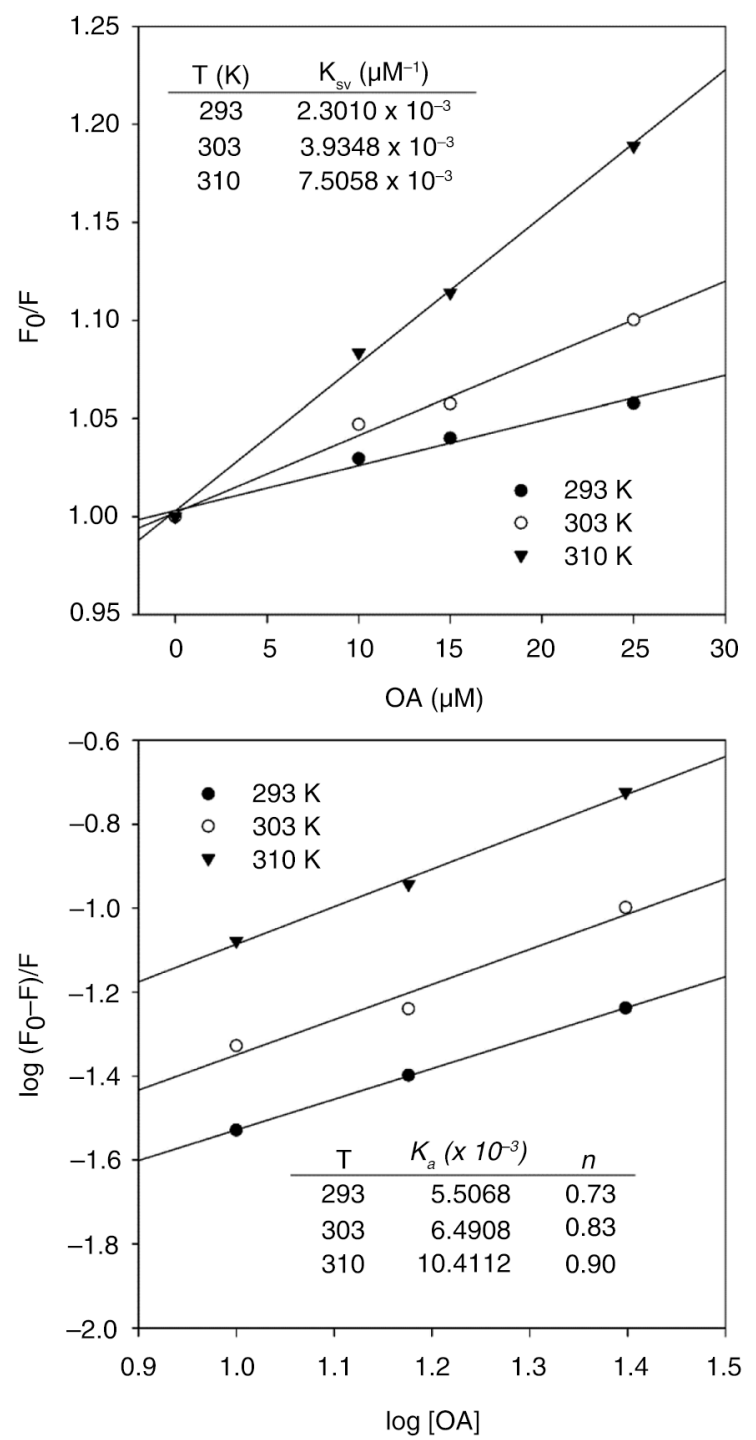

Figure 6. Stern-Volmer plots for the fluorescence quenching of $\alpha$-glucosidase by OA.

$\Delta G=\Delta H-T \Delta S$ relationship. Both $\Delta H$ and $\Delta S$ were positive, proposing that the $\mathrm{OA} / \alpha$-glucosidase association has a hydrophobic nature. Likewise, $\Delta G$ values were positive, signifying that the triterpene/protein association is endergonic in the assayed temperature range $\left(20-37^{\circ} \mathrm{C}\right)$.

\section{DISCUSSION}

The experimental and clinical evidence indicates an inverse association between insulin sensitivity and oxidative stress, up to the point that diabetes is acknowledged as a phenotype of dysfunctions in mitochondria and endoplasmic reticulum, associated with an excessive ROS production or an impairment of the endogenous antioxidant system (Lowell and Shulman, 2005). Because post-prandial 
hyperglycaemia induces oxidative stress, the search for natural bio-molecules with the dual ability to decrease glucose absorption and oxidative damage has become an important research topic. Within that scenario, this paper reports new findings about $\mathrm{OA}$ as a radical scavenger and inhibitor of the $\alpha$-glucosidase activity.

The antioxidant power of $\mathrm{OA}$ is subject to controversy since it is markedly influenced by the singularities of the experimental systems employed in its evaluation. We have evaluated the OA ability to scavenge three radical species (ABTS+, DPPH and peroxyl), finding that it can capture ABTS+ radicals in a moderate and dose-dependent manner, but it lacks the ability to scavenge DPPH species. These results are in agreement with those previously provided by other authors (Yang et al., 2007; Wang et al., 2010; Allouche et al., 2011).

The role of triterpene against peroxyls deserves a more detailed discussion. The ORAC assay has demonstrated that OA moderately captures the radicals generated from AAPH, although it failed with those formed from complex lipid matrixes in the Rancimat procedure. In fact, this last protocol has revealed that OA might exert a pro-oxidant action. These results do not coincide with those of Yin and Chan (2007), who have studied the triterpene potential for reducing peroxyl radicals using a modified TBARS assay on liposomes. They determined that OA had a high and dose-dependent activity when liposome peroxidation was induced by AAPH and 2,2'-azobis-(2,4-dimethylvaleronitrile). Closer to the Rancimat method, Assimopoulou et al. (2005) investigated the OA effect on the oxidation of lard and sunflower oil in an oven at $65^{\circ} \mathrm{C}$. They monitored the evolution of peroxide value, reporting that OA did not exhibit a clear antioxidant activity. Wang et al. (2010) examined the effect of OA in liver microsomes of Sprague-Dawley rats, comparing the triterpene action with those of well-known antioxidants, and found that the protection offered by OA against peroxyls depended on the substance used for inducing lipid peroxidation. This study also evidenced that some molecules recognized as antioxidants (vitamin $\mathrm{C}$ or $\alpha$-lipoic acid) could act as pro-oxidants depending of the nature of the lipid oxidizing agent. Once again, different experimental approaches lead to different conclusions, many of which are conflicting.

Another mechanism by which OA may contribute to controlling oxidative stress is by decreasing post-prandial hyperglycaemia, through the inhibition of carbohydrate-hydrolyzing enzymes. In this paper, we present results proving that OA is not an $\alpha$-amylase inhibitor. This finding is in agreement with other published data (Hou et al., 2009; Wang et al., 2011) although there are also contradictory results supporting that OA might effectively repress this activity (Khati et al., 2013; Ali et al., 2006;
Komaki et al., 2003), with quite variable $\mathrm{IC}_{50}$ values in the range of $10 \mu \mathrm{M}-2.6 \mathrm{mM}$.

Unlike $\alpha$-amylase, OA exerts a strong and dosedependentinhibition of $\alpha$-glucosidase. We have determined an $\mathrm{IC}_{50} 10.11 \pm 0.30 \mu \mathrm{M}$, a very similar value to those reported by other authors (Ali et al., 2002; Hou et al., 2009; Kang et al., 2012). In addition, we present here new contributions to the understanding of the $\mathrm{OA} / \alpha$-glucosidase interaction, performing a deeper kinetic study and fluorescent measurements. We found that $\mathrm{OA}$ is a non-competitive inhibitor of $\alpha$-glucosidase $(\mathrm{Ki}=9.12 \pm 0.24 \mu \mathrm{M})$, which binds the enzyme in a neighboring region of the active site. The comparison of the inhibitory efficiency of OA with those of other natural and synthetic structural analogs allows us to outline some molecular features with impact on inhibition: a) the relevancy of the hydrophobic skeleton with a hydroxyl group in C3 and a carboxyl group in C28 is acknowledged; b) the introduction of a second phenolic hydroxyl at $\mathrm{C} 2$, as in maslinic or corosolic acids, might increase the inhibitory power of the triterpene (Ali et al., 2006); c) the substitution of the methyl at C23 by a more bulky ligand (an acetyl group, for example) would diminish this ability (Ali et al., 2002); and d) the $\beta$-orientation of the phenolic hydroxyl in $\mathrm{C} 3$ seems to be clearly influential for the inhibition, since corosolic acid with a $\beta$-oriented hydroxyl such as OA exhibits an $\mathrm{IC}_{50}$ value of $7.47 \mu \mathrm{M} 45$, whereas 3 -epi-corosolic acid, its $\alpha$-stereoisomer, displays a $\mathrm{IC}_{50} 63.9 \mu \mathrm{M}$ (Chowdhury et al., 2014).

The fluorescent measurements of the $\mathrm{OA} / \alpha-$ glucosidase complex provide useful information about the binding mechanism and binding site. The intrinsic fluorescence of a folded protein is the result of that emitted by its individual aromatic residues, with most of the emissions due to the excitation of tryptophans and few due to tyrosines and phenylalanines. On the other hand, tryptophans located in inner regions of proteins with hydrophobic microenvironments emit maximum fluorescence near 331 $\mathrm{nm}$, whereas those residues located on the protein surface exposed to a high-polarity aqueous media emit at longer wavelengths $(\approx 350 \mathrm{~nm})$ (Lacovicz, 2006). Therefore, the wavelength of maximum emission can be interpreted in terms of the ratio between these two classes of tryptophans. Moreover, intrinsic fluorescence often decreases when a protein interacts with another compound. The process (quenching) happens during the excited state lifetime (collisional or dynamic quenching) or due to the formation of a complex in the ground state (static quenching).

In our case, the maximum fluorescence emitted by $\alpha$-glucosidase as well as quenching by interaction with $\mathrm{OA}$ are detected at $333 \mathrm{~nm}$, indicating that the tryptophyls involved in the triterpene binding are almost exclusively located inside a hydrophobic pocket. The Stern-Volmer plots determined a single class of binding site on $\alpha$-glucosidase ( $n$ tending 
towards 1), with all the participating tryptophans identically accessible (linearity of the plots within the experimental range of OA concentrations). We have also found that the $\alpha$-glucosidase/triterpene interaction responds to a collisional mechanism which is favored at warmer temperatures, such as that operating in the human body (rising values of quenching constant at increasing temperature). The study of thermodynamic parameters corroborated the idea that inhibition of $\alpha$-glucosidase by $\mathrm{OA}$ is an endothermic and entropy-driven, a nonspontaneous process of predominant hydrophobic nature. However, complementary contribution of hydrogen bridges cannot be ruled out because the reaction medium is aqueous and both $\mathrm{OA}$ and $\alpha$-glucosidase molecules include prominent hydroxyl groups. These outcomes are coherent with reported data postulating the existence of tryptophans neighboring the $\alpha$-glucosidase active site, which are likely to be more relevant for maintaining an efficient substrate accommodation rather than for the catalysis itself (Faridmoayer and Scaman, 2005). So, the OA binding to these tryptophyls would alter the folding of the protein, hindering the access of the substrate to the inner cleft with the active site.

In addition to studies on the inhibition of amylase and glucosidase activities, in recent years new data have been reported showing that OA can also repress the expression of these proteins in the small intestine (Gabás-Rivera et al., 2013; Khathi et al., 2013), in addition to the glucose transporters SGLT1 and GLUT2, involved in the absorption of the saccharide from the lumen of the small intestine to the bloodstream.

In summary, our results support the hypothesis that OA may facilitate a better control of postprandial hyperglycaemia and oxidative stress, so contributing to the preservation of insulin signalling. While its aptitude for inhibiting $\alpha$-glucosidase is powerful, its ability for acting as scavenger of radical species is only moderate. This last aspect indicates that the efficient antioxidant activity exhibited by OA in cell cultures and experimental animals is likely to result from a more intricate and multi-factorial mechanism. In recent years, there have been increasing evidence to support the assertion that OA reinforces the cellular antioxidant response by modulating the expression of key genes, including antioxidant proteins and NADPH-producing enzymes, responsible for maintaining the GSH level and its transportation into mitochondria. In this nutri genomic effect of $\mathrm{OA}$, the activation of the nuclear factor erythroid 2 p45-related factor 2 (Nrf2) seems to play a protagonist role (Wang et al., 2010; Castellano et al., 2013).

Obesity, insulin resistance and T2DM are considered the first pandemics of the 21st century. Therefore, National Health Systems are obliged to introduce urgent measures which delay or avoid their progression. In this sense, OA might be used in future preventive and therapeutic strategies. Despite the limited number of studies in humans, it is accepted that OA is a safe phytochemical. None of these trials have recorded significant adverse effects $(\mathrm{Xu}, 1980$; Minich et al., 2007; Song et al., 2006; Chen et al., 2010; Rada et al., 2015). Nevertheless, further investigations in humans will be necessary to extend the use of OA in the design of new drugs and functional foods, which allow for personalized diets and nutrigenomic approaches for the prevention of high-prevalence chronic disorders such as diabetes.

\section{ACKNOWLEDGMENTS}

The Spanish Ministry of Economy and Competitiveness (Carlos III Institute of Health) financed the research project PI10/01415. The authors wish to thank the Andalusian Public System of Health (Spain) and the ACESUR Group for making the PREDIABOLE Study possible.

\section{REFERENCES}

Albi T, Guinda A, Lanzón A. 2001. Procedimiento de obtención y determinación de ácidos terpénicos de la hoja de olivo (Olea europaea). Grasas Aceites 52, 275-278.

Ali H, Houghton PJ, Soumyanath A. 2006. $\alpha$-Amylase inhibitory activity of some Malaysian plants used to treat diabetes; with particular reference to Phyllanthus amarus. J. Ethnopharmacology 107, 449-455. http://dx.doi. org/10.1016/j.jep.2006.04.004

Ali MS, Jahangir M, Hussan SS, Choudhary MI. 2002. Inhibition of $\alpha$-glucosidase by oleanolic acid and its synthetic derivatives. Phytochemistry 60, 295-299. http:// dx.doi.org/10.1016/S0031-9422(02)00104-8

Allouche Y, Warleta F, Campos M, Sánchez-Quesada C, Uceda M, Beltrán G, Gaforio JJ. 2011. Antioxidant, antiproliferative and pro-apoptotic capacities of pentacyclic triterpenes found in the skin of olives on MCF-7 human breast cancer cells and their effects on DNA damage. J. Agric. Food Chem. 59, 121-130. http://dx.doi.org/10.1021/jf102319y

Assimopoulou AN, Zlatanos SN, Papageorgiu VP. 2005. Antioxidant activity of natural resins and bioactive triterpenes in oil substrates. Food Chem. 92, 721-727. http:// dx.doi.org/10.1016/j.foodchem.2004.08.033

Brown BG, Zhao XQ, Chait A, Fischer LD, Cheung MC, Morse JS, Dowdy AA, Marino EK, Bolson EL, Alaupovic P, Frohlich J, Albers JJ. 2001. Simvastatin and niacin, antioxidant vitamins, or the combination for the prevention of coronary disease. N. Eng. J. Med. 345, 1583-1592. http:// dx.doi.org/10.1056/NEJMoa011090

Castellano JM, Guinda A, Delgado T, Rada M, Cayuela JA. 2013. Biochemical basis of the antidiabetic activity of oleanolic acid and related pentacyclic triterpenes. Diabetes $\mathbf{6 2}$, 1791-1799. http://dx.doi.org/10.2337/db12-1215

Ceriello, A.; Testa, R. 2009. Antioxidant anti-inflammatory treatment in type 2 diabetes. Diabetes Care 32, S232-S236. http://dx.doi.org/10.2337/dc09-S316

Chen RJ, Liu X, Li PM, Zhang L, Zhao L and Zhang XL. 2010. Pharmacokinetic profiles of oleanolic acid formulations in healthy Chinese male volunteers. Chinese Pharmaceutical J. 45, 621-626.

Chowdhury SS, Islam MN, Jung HA, Choi JS. 2014. In vitro antidiabetic potential of the fruits of Crataegus pinnatifida. Res. Pharm. Sci. 9, 11-22.

Dzubak P, Hajduch M, Vydra D, Hustova A, Kvasnica M, Biedermann D, Markova L, Urban M, Sarek J. 2006. 
Pharmacological activities of natural triterpenoids and their therapeuric implications. Nat. Prod. Rep. 23, 394-411. http://dx.doi.org/10.1039/b515312n

Faridmoayer A, Scaman CH. 2005. Binding residues and catalytic domain of soluble Saccharomyces cerevisiae processing alpha-glucosidase I. Glycobiology 15, 1341-1348. http://dx.doi.org/10.1093/glycob/cwj009

Fujisawa T, Ikegami H, Inoue K, Kawabata Y, Ogihara T. 2005. Effect of two $\alpha$-glucosidase inhibitors, voglibose and acarbose, on postprandial hyperglycemia correlates with subjective abdominal symptoms. Metabolism 54, 387-390. http://dx.doi.org/10.1016/j.metabol.2004.10.004

Gabás-Rivera C, Martínez-Beamonte R, Ríos JL, Navarro MA, Surra JC, Arnal C, Rodríguez-Yoldi MJ, Osada J. 2013. Dietary oleanolic acid mediates circadian clock gene expression in liver independently of diet and animal model but requires apoliproprotein A1. J. Nutrit. Biochem. 21, 2100-2109. http://dx.doi.org/10.1016/j.jnutbio.2013.07.010

Guinda A, Albi T, Lanzón A. Procedure for the obtaining of oleanolic acid from the Olea europaea leaf. Spanish Patent 2001/2 160553

Guinda A, Rada M, Delgado T, Gutiérrez-Adánez P, Castellano JM. 2010. Pentacyclic triterpenoids from olive fruit and leaf. J. Agric. Food Chem. 58, 9685-9691. http://dx.doi. org/10.1021/jf102039t

Hou W, Li Y, Zhang Q, Wei X, Peng A, Chen L, Wei Y. 2009. Triterpene acids isolated from Lagerstroemia speciose leaves as $\alpha$-glucosidase inhibitors. Phytotherapy Res. 23, 614-618. http://dx.doi.org/10.1002/ptr.2661

Kang W, Song S, Gu X. 2012. $\alpha$-Glucosidase inhibitory in vitro and antidiabetic activity in vivo of Osmanthus fragans. $J$. Med. Plant Res. 6, 2850-2856.

Kang WY, Song YL, Zhang L. 2011. Alpha-glucosidase inhibitory and antioxidant properties and antidiabetic activity of Hypericum ascyron L. Med. Chem. Res. 20, 809-816. http:// dx.doi.org/10.1007/s00044-010-9391-5

Khathi A, Serumula MR, Myburg RB, Van Heerden FR, Musabayane T. 2013. Effects of Sizigium aromaticumderived triterpenes on postprandial blood glucose in streptozotocin-induced diabetic rats following carbohydrate challenge. PLOS ONE 8, e81632. http://dx.doi. org/10.1371/journal.pone.0081632

Komaki E, Yamaguchi S, Maru I, Kinoshita M, Kakehi K, Ohta Y, Tsukada Y. 2003. Identification of anti- $\alpha$-amylase components from olive leaf extracts. Food Sci. Technol. Res. 9, 35-39. http://dx.doi.org/10.3136/fstr.9.35

Lacovicz JR. 2006. Principles of fluorescence spectroscopy (3rd edition). Springer. New York.

Liu J. 2005. Oleanolic acid and ursolic acid: Research perspectives. J. Ethnopharmacology 100, 92-94. http://dx.doi. org/10.1016/j.jep.2005.05.024

Lowell BB, Shulman GI. 2005. Mitochondrial dysfunction and type 2 diabetes. Science 307, 384-387. http://dx.doi. org/10.1126/science.1104343

Minich DM, Bland JS, Katke J, Darlang G, Hall A, Lerman RH, Lamb J, Carroll B, Trypp M. 2007. Clinical safety and efficacy of NG440: a novel combination of rho isoalpha acids from hops, rosemary, and oleanolic acid for inflammatory conditions. Can. J. Physiol. Pharmacol. 85, 872-883. http://dx.doi.org/10.1139/Y07-055

Prior RL, Hoang H, Gu L, Wu X, Bacchiocca M, Howard L, Hampsch-Woodill M, Huang D, Ou B, Jacob R. 2003. Assay for hydrophilic and lipophilic antioxidant capacity (oxygen radical absorbance capacity (ORACFL)) of plasma and other biological and food samples. J. Agric. Food Chem. 51, 3273-3279. http://dx.doi.org/10.1021/ jf0262256

Quagliaro L, Piconi L, Assalone R, Martinelli L, Motz E, Ceriello A. 2003. Intermittent high glucose enhances apoptosis related to oxidative stress in human umbilical vein endothelial cells. Diabetes 52, 2795-2804. http://dx.doi. org/10.2337/diabetes.52.11.2795

Rada M, Castellano JM, Perona J, Guinda A. 2015. GC-FID determination and pharmacokinetic studies of oleanolic acid in human serum. Biomed. Chromatog. 29, 1687-1692. http://dx.doi.org/10.1002/bmc.3480

Re R, Pellegrini N, Proteggente A, Pannala A, Yang M, Rice-Evans C. 1999. Antioxidant activity applying and improved ABTS radical cation decolorization assay. Free Rad. Biol. Med. 26, 1231-1237. http://dx.doi.org/10.1016/ S0891-5849(98)00315-3

Schiekofer S, Andrassy M, Chen J, Rudofsky G, Schneider J, Wendt T, Stefan N, Humpert P, Fritche A, Stumvoll M, Schleicher E, Häring H-U, Nawroth PP, Bierhaus A. 2003. Acute hyperglycemia causes intracellular formation of CML and activation of ras, p42/44 MAPK, and nuclear factor $\kappa \mathrm{B}$ in PBMCs. Diabetes 52, 621-633. http://dx.doi. org/10.2337/diabetes.52.3.621

Sharma O, Bhat TK. 2009. DPPH antioxidant assay revisited. Food Chem. 13, 1202-1205. http://dx.doi.org/10.1016/j. foodchem.2008.08.008

Song M, Hang TJ, Wang Y, Jiang L, Wu XL, Zhang Z, Shen J, Zhang Y. 2006. Determination of oleanolic acid in human plasma and study of its pharmacokinetics in Chinese healthy male volunteers by HPLC tandem mass spectrometry. J. Pharmaceut. Biomed. Anal. 40, 190-196. http:// dx.doi.org/10.1016/j.jpba.2005.06.034

Wang X, Li Y-L, Wu H, Liu J-Z, Hu J-X, Liao N, Peng J, Cao P-P, Liang X, Hai C-X. 2011. Antidiabetic effect of oleanolic acid: A promising use of a traditional pharmacological agent. Phytother. Res. 25, 1031-1040. http://dx.doi.org/10.1002/ ptr.3385

Wang X, Ye X-L, Liu R, Chen H-L, Bai H, Liang X, Zhang X-D, Wang Z, Li W-L, Hai C-X. 2010. Antioxidant activities of oleanolic acid in vitro: Possible role of Nrf2 and MAP kinases. Chemico-Biological Interactions 184, 328-337. http://dx.doi.org/10.1016/j.cbi.2010.01.034

Watson JD. 2014. Type 2 diabetes as a redox disease. The Lancet 383, 841-843. http://dx.doi.org/10.1016/ S0140-6736(13)62365-X

Xu LZ, Wan ZX. 1980. The effect of oleanolic acid on acute hepatitis (70 cases). Human Medicine 7, 50-52.

Yan J, Zhang G, Pan J, Wang Y. 2014. $\alpha$-Glucosidase inhibition by luteolin: Kinetic, interactions and molecular docking. Int. J. Biol. Macromol. 64, 213-223. http://dx.doi. org/10.1016/j.ijbiomac.2013.12.007

Yang ZG, Li HR, Wang LY, Li YH, Lu SG, Wen XF, Wang J, Daikonoya A, Itanaka S. 2007. Triterpenoids from Hippophae rhamnoides L. and their nitric oxide production-inhibitory and DPPH radical-scavenging activities. Chem. Pharm. Bull. 55, 15-18. http://dx.doi.org/10.1248/ cpb.55.15

Yin M-C, Chan K-C. 2007. Nonenzymatic antioxidative and antiglycative effects of oleanolic acid and ursolic acid. J. Agric. Food Chem. 55, 7177-7181. http://dx.doi. org/10.1021/jf071242m 